\title{
BMJ Open Proton pump inhibitors versus histamine-2 receptor antagonists for stress ulcer prophylaxis during extracorporeal membrane oxygenation: a propensity score-matched analysis
}

\author{
Yutaka Kondo (1) , ${ }^{1,2}$ Hiroyuki Ohbe, ${ }^{2}$ Hiroki Matsui, ${ }^{2}$ Kiyohide Fushimi, ${ }^{3}$ \\ Hiroshi Tanaka, ${ }^{1}$ Hideo Yasunaga ${ }^{2}$
}

To cite: Kondo $\mathrm{Y}$, Ohbe $\mathrm{H}$, Matsui $\mathrm{H}$, et al. Proton pump inhibitors versus histamine-2 receptor antagonists for stress ulcer prophylaxis during extracorporeal membrane oxygenation: a propensity scorematched analysis. BMJ Open 2020;10:e037534. doi:10.1136/ bmjopen-2020-037534

- Prepublication history and supplemental material for this paper are available online. To view these files, please visit the journal online (http://dx.doi org/10.1136/bmjopen-2020037534).

Received 06 February 2020 Revised 04 August 2020 Accepted 26 August 2020

\section{Check for updates}

(c) Author(s) (or their employer(s)) 2020. Re-use permitted under CC BY-NC. No commercial re-use. See rights and permissions. Published by BMJ.

${ }^{1}$ Department of Emergency and Critical Care Medicine, Juntendo University Urayasu Hospital, Urayasu, Chiba, Japan

${ }^{2}$ Department of Clinical Epidemiology and Health Economics, School of Public Health, The University of Tokyo, Tokyo, Japan

${ }^{3}$ Health Care Policy and Informatics, Tokyo Medical and Dental University, Tokyo, Japan

Correspondence to

Dr Yutaka Kondo;

kondokondou2000@yahoo.co.jp

\section{ABSTRACT}

Purpose Patients receiving extracorporeal membrane oxygenation (ECMO) generally receive proton pump inhibitors (PPIs) or histamine-2 receptor antagonists $\left(\mathrm{H}_{2} \mathrm{RAs}\right)$ to avoid major gastrointestinal bleeding. Our aim was to compare outcomes between patients receiving PPIs and $\mathrm{H}_{2} \mathrm{RAs}$ for stress ulcer prophylaxis during ECMO.

Materials and methods We performed a retrospective cohort study using the Japanese Diagnosis Procedure Combination Database, using data recorded from 1 July 2010 to 31 March 2017. We defined patients who received PPIs within 2 days after starting ECMO as the PPIs group and those who received $\mathrm{H}_{2} \mathrm{RAs}$ within 2 days after starting ECMO as the $\mathrm{H}_{2} \mathrm{RAs}$ group. We performed propensity score matching to compare outcomes. The primary outcomes were gastrointestinal bleeding requiring endoscopic haemostasis and in-hospital mortality. The secondary outcomes were red blood cell transfusion, hospitalacquired pneumonia and Clostridium difficile infection during hospitalisation.

Results Of 11328 eligible patients, 9738 received PPIs and 1590 received $\mathrm{H}_{2} \mathrm{RAs}$. Propensity score matching created 1556 pairs. No significant differences were seen regarding endoscopic haemostasis $(1.2 \%$ vs $0.8 \%$; $p=0.37)$, in-hospital mortality ( $53.0 \%$ vs $53.1 \% ; p=0.94)$, red blood cell transfusion rates $(91.4 \%$ vs $89.7 \% ; p=0.11)$, hospital-acquired pneumonia ( $13.0 \%$ vs $12.4 \% ; p=0.59)$ or $C$. difficile infection $(0.1 \%$ vs $0.2 \% ; p=0.32)$ between the PPIs and $\mathrm{H}_{2} \mathrm{RAs}$ groups, respectively.

Conclusion We found no differences in the evaluated outcomes between the PPIs and $\mathrm{H}_{2} \mathrm{RAs}$ groups. Both PPIs and $\mathrm{H}_{2} \mathrm{RAs}$ are treatment options for stress ulcer prophylaxis in patients undergoing ECMO.

\section{PURPOSE}

Extracorporeal membrane oxygenation (ECMO) therapy is widely used for circulatory and respiratory support for critically ill patients. Although the use of ECMO is increasing, in-hospital mortality and bleeding complications among critically ill patients receiving ECMO remain high. ${ }^{1}$ Clinically
Strengths and limitations of this study

Both proton pump inhibitors (PPIs) and histamine-2 receptor antagonists $\left(\mathrm{H}_{2} \mathrm{RAs}\right)$ are treatment options for stress ulcer prophylaxis in patients undergoing extracorporeal membrane oxygenation (ECMO).

- To the best of our knowledge, this study is the first report comparing PPIs and $\mathrm{H}_{2} \mathrm{RAs}$ for stress ulcer prophylaxis during ECMO.

- The proportion of patients with gastrointestinal bleeding may have been underestimated because the current study included only patients with severe bleeding requiring endoscopic haemostasis.

important gastrointestinal bleeding (CIGIB) often results in death because ECMO requires anticoagulants. To avoid CIGIB, patients receiving ECMO generally also receive stress ulcer prophylaxis drugs. The use of ECMO equipment in critically ill patients may result in gastrointestinal ischaemia because ECMO can change the blood flow. Proton pump inhibitors (PPIs) and histamine-2 receptor antagonists $\left(\mathrm{H}_{2} \mathrm{RAs}\right)$ are the main stress ulcer prophylactic drugs. The American Society of Health-System Pharmacists' guidelines recommend using PPIs as the first-line drugs for critically ill patients. ${ }^{34}$ A systematic review of randomised controlled trials also showed that PPIs were superior to $\mathrm{H}_{2} \mathrm{RAs}$ in preventing CIGIB without increasing the risk of adverse effects. ${ }^{5}$

Recently, some studies have thrown doubt on the efficacy of PPIs. ${ }^{67}$ In 2014, an observational study reported that PPIs were associated with a higher risk of CIGIB (OR, 2.24 (95\% CI 1.81 to 2.76)) compared with $\mathrm{H}_{2} \mathrm{RAs}$, in critically ill patients. ${ }^{6}$ In 2018, a larger observational study showed that PPIs were associated with a higher risk of CIGIB compared 
with $\mathrm{H}_{2} \mathrm{RAs}$ in critically ill patients. ${ }^{7}$ A recent randomised controlled trial showed no difference in CIGIB between PPIs and $\mathrm{H}_{2} \mathrm{RAs}^{8}$; however, to our knowledge, no previous study has assessed the superiority of PPIs over $\mathrm{H}_{2} \mathrm{RAs}$ in patients receiving ECMO.

The aim of the present study was to compare outcomes between PPIs and $\mathrm{H}_{2} \mathrm{RAs}$ to prevent stress ulcers in patients receiving ECMO using a Japanese National Inpatient Database.

\section{MATERIALS AND METHODS}

The requirement to obtain patients' informed consent was waived because of the anonymous nature of the datasets. Patients and the public were not involved in the design or planning of the study.

\section{Study design and data collection}

This retrospective cohort study was performed using the Japanese Diagnosis Procedure Combination Database, which comprises administrative claims and discharge abstract data from more than 1200 acute-care hospitals in Japan. ${ }^{9}$ The database covers approximately $90 \%$ of all tertiary-care emergency hospitals and includes the following patient variables: age, sex, weight, height, consciousness level, primary diagnosis, comorbidities at admission, postadmission complications, procedures, prescriptions and discharge status. The main diagnosis, primary diagnosis on admission, comorbidities present on admission and comorbidities diagnosed during each episode of hospitalisation are recorded using the International Classification of Diseases and Related Health Problems, 10th Revision (ICD-10) codes, with text data in Japanese. A previous validation study for the database showed a high specificity for the recorded diagnoses and a high sensitivity and specificity for the recorded procedures. $^{10}$

\section{Study participants}

Data recorded from 1 July 2010 to 31 March 2017 in the database were used in the present study. We studied critically ill patients receiving ECMO and excluded patients (1) who were younger than 18 years of age, (2) who died or were discharged within 2 days of receiving ECMO, (3) who had a history of gastric ulcer or gastritis before stress ulcer prophylaxis, (4) who received sucralfate within 2 days of ECMO, (5) who underwent endoscopic haemostasis before ECMO, (6) who received neither PPIs nor $\mathrm{H}_{2} \mathrm{RAs}$, (7) who received both PPIs and $\mathrm{H}_{2} \mathrm{RAs}$ within 2 days of ECMO (because gastrointestinal bleeding within 2 days of ECMO suggests existence of gastritis before ECMO) and (8) whose reason for receiving ECMO was unspecified. Eligible patients were divided into those who received PPIs within 2 days after starting ECMO (PPIs group) and those who received $\mathrm{H}_{2} \mathrm{RAs}$ within 2 days after starting ECMO ( $\mathrm{H}_{2} \mathrm{RAs}$ group). We included patients receiving both PPIs and $\mathrm{H}_{2} \mathrm{RAs}$ after 2 days of ECMO.
Patients who used PPIs first and then used $\mathrm{H}_{2}$ RAs were categorised to the PPIs group, and vice versa.

\section{Variables and outcomes}

For this study, we examined the following patient characteristics: age, sex, Japan Coma Scale (JCS) score, body mass index $\left(\mathrm{kg} / \mathrm{m}^{2}\right)$, Charlson Comorbidity Index score, fiscal year, aetiology (online supplemental table 1), ambulance use, academic hospital, cardiac surgery before ECMO, interventions (mechanical ventilation, continuous renal replacement therapy, chest tube drainage, intra-aortic balloon pumping, defibrillation, chest compression, tracheostomy, arterial pressure monitoring and hypothermia treatment) within 2 days of ECMO, drugs (dopamine, dobutamine, norepinephrine, epinephrine and vasopressin) within 2 days of ECMO and transfusion (red blood cells, fresh-frozen plasma, platelets and albumin) within 2 days of ECMO. The JCS score was categorised into four groups: 0 (alert), 1-3 (dizziness), 10-30 (somnolence) and 100-300 points (coma). JCS scores are well correlated with Glasgow Coma Scale scores, and a JCS score of 100 is equivalent to a Glasgow Coma Scale score of $6-9 .{ }^{11}$ Charlson Comorbidity Index scores predict the risk of death by weighting or classifying comorbidities. ${ }^{12}$ Several validation studies for the Charlson Comorbidity Index have been reported. ${ }^{13} 14$

We identified diagnoses of hospital-acquired pneumonia with the ICD-10 codes J152, J159, J180, J181, J189, J209, J690 and J958. We also identified diagnoses of Clostridium difficile infection with the ICD-10 code A047.

The primary outcomes were gastrointestinal bleeding requiring endoscopic haemostasis and in-hospital mortality. The secondary outcomes were red blood cell transfusion, hospital-acquired pneumonia and C. difficile infection during hospitalisation.

\section{Statistical analysis}

We used propensity score matching to compare the outcomes between the PPIs and $\mathrm{H}_{2} \mathrm{RAs}$ groups and a multivariable logistic regression model to predict propensity scores for receiving PPIs. Predictor variables included age, sex, fiscal year, admission to a teaching hospital, ambulance use, body mass index at admission, JCS at admission, Charlson Comorbidity Index, reason for ECMO, cardiac surgery before ECMO, interventions (mechanical ventilation, continuous renal replacement therapy, chest tube drainage, intra-aortic balloon pumping, defibrillation, chest compression, tracheostomy, arterial line and hypothermia treatment) within 2 days of ECMO, drugs (dopamine, dobutamine, norepinephrine, epinephrine and vasopressin) within 2 days of ECMO and transfusion (red blood cells, fresh-frozen plasma, platelets and albumin) within 2 days of ECMO. One-to-one nearest-neighbour matching without replacement was performed for patients' estimated propensity scores using a calliper width set at $20 \%$ of the SD of the propensity scores. ${ }^{1516}$ 


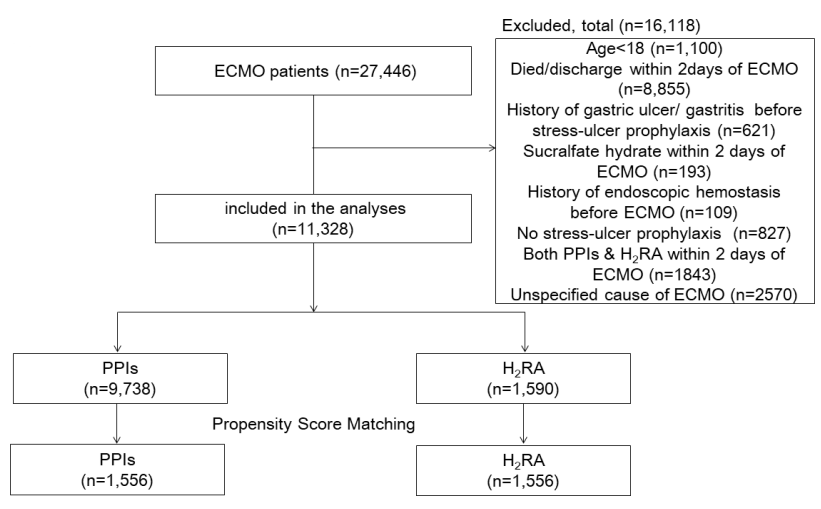

Figure 1 Flow diagram of patients receiving extracorporeal membrane oxygenation (ECMO). $\mathrm{H}_{2} \mathrm{RA}$, histamine-2 receptor antagonist; PPIs, proton pump inhibitors.

A standardised difference of $-10 \%$ to $\leq 10 \%$ was considered to denote negligible imbalances in the variables between the propensity score-matched PPIs and $\mathrm{H}_{2} \mathrm{RAs}$ groups. ${ }^{17}$ We performed propensity score matching using the Stata (StataCorp) module PSMATCH2. ${ }^{18}$

We used a generalised estimating equation approach for comparisons of the primary and secondary outcomes, accompanied by cluster-robust standard errors that treated both propensity score-matched pairs and individual hospitals as clusters. ${ }^{19}$ ORs and 95\% CIs were calculated for the primary and secondary outcomes. These estimates were obtained by generalised estimating equation models with logit link functions, irrespective of outcome types. ${ }^{20}$ We performed sensitivity analyses using the variables within 1 day of ECMO instead of the variables within 2 days of ECMO.

We performed sensitivity analyses by the stabilised inverse probability of treatment weighting (IPTW) method to account for differences in baseline covariates between the groups. Stabilised IPTW is a propensity score-based method to adjust for measured potential confounding factors and creates a pseudodataset by preserving the sample size. ${ }^{21}$ Stabilised IPTW estimates the average treatment effects over a marginal distribution of measured covariates in the matched cohort. ${ }^{22}$

Continuous variables are presented as medians and IQRs. Categorical variables are presented as numbers and percentages. Baseline characteristics and crude outcomes were compared using the Mann-Whitney test for continuous variables with a skewed distribution and the $\chi^{2}$ test or Fisher's exact test for categorical variables between the groups.

The two-sided significance level for all tests was $\mathrm{p}<0.05$. All analyses were performed using Stata/MP V.15 (StataCorp).

\section{Patient and public involvement}

Patients or members of the public were not involved in the design or implementation. Patients and the general public will be informed of the results via publication.
RESULTS

A total of 11328 patients met the inclusion criteria during the study period. Of these, 9738 (86.0\%) patients received PPIs and $1590(14.0 \%)$ patients received $\mathrm{H}_{2} \mathrm{RAs}$ (figure 1). Patients' characteristics before and after propensity score matching are shown in table 1 . Before propensity score matching, the PPIs group had higher proportions of patients with ischaemic heart disease (40.4\% in the PPIs group and $34.7 \%$ in the $\mathrm{H}_{2} \mathrm{RAs}$ group) and congestive heart failure $(15.8 \%$ in the PPIs group and $12.2 \%$ in the $\mathrm{H}_{2} \mathrm{RAs}$ group), whereas the $\mathrm{H}_{2} \mathrm{RAs}$ group had higher proportions of patients with aortic dissection/aneurysm (5.4\% in the PPIs group and $11.4 \%$ in the $\mathrm{H}_{2} \mathrm{RAs}$ group) and trauma/intoxication (3.4\% in the PPIs group and $7.0 \%$ in the $\mathrm{H}_{2} \mathrm{RAs}$ group). The PPIs group was more likely to receive continuous renal replacement therapy $\left(32.2 \%\right.$ in the PPIs group and $25.4 \%$ in the $\mathrm{H}_{2} \mathrm{RAs}$ group), intra-aortic balloon pumping $(65.6 \%$ in the PPIs group and $49.1 \%$ in the $\mathrm{H}_{2} \mathrm{RAs}$ group), norepinephrine ( $77.1 \%$ in the PPIs group and $69.9 \%$ in the $\mathrm{H}_{2} \mathrm{RAs}$ group), and epinephrine $(61.6 \%$ in the PPIs group and $55.6 \%$ in the $\mathrm{H}_{2} \mathrm{RAs}$ group). The $\mathrm{H}_{2} \mathrm{RAs}$ group was more likely to receive arterial blood pressure lines $(84.7 \%$ in the PPIs group and $89.2 \%$ in the $\mathrm{H}_{2} \mathrm{RAs}$ group), cardiac surgery (13.1\% in the PPIs group and $28.5 \%$ in the $\mathrm{H}_{2} \mathrm{RAs}$ group) and dopamine (56.4\% in the PPIs group and $65.7 \%$ in the $\mathrm{H}_{2} \mathrm{RAs}$ group). The proportions of patients receiving PPIs increased annually during the study period compared with the proportions of patients receiving $\mathrm{H}_{2} \mathrm{RAs}$. After propensity score matching, patients' characteristics were well balanced between the two groups.

Crude in-hospital mortality and the proportion of patients receiving red blood cell transfusions were significantly higher in the PPIs group $(57.2 \%)$ than $\mathrm{H}_{2} \mathrm{RAs}$ group $(52.6 \%$ ) (table 2). The proportions of patients undergoing endoscopic haemostasis, developing hospitalacquired pneumonia and acquiring $C$. difficile infection did not differ significantly between the two groups. In the propensity score-matching analysis, no outcomes were significantly different between the groups (table 2).

A generalised estimating equation analysis after propensity score matching showed no significant differences in any outcomes between the PPIs and $\mathrm{H}_{2} \mathrm{RAs}$ groups (table 3). The results of the sensitivity analyses using the variables within 1 day of ECMO were similar to those using the variables within 2 days (online supplemental table 2). The stabilised IPTW analysis also showed no significant differences in any of the outcomes (table 4).

\section{DISCUSSION}

The use of PPIs increased annually during our study period; however, our results showed no obvious benefits of PPIs regarding reducing the need for endoscopic haemostasis or in-hospital mortality. In addition, we found no significant differences in the number of transfusions, the proportions of patients developing in-hospital acquired pneumonia or the proportions of patients acquiring $C$. 
Table 1 Patients' backgrounds in the unmatched and propensity score-matched groups

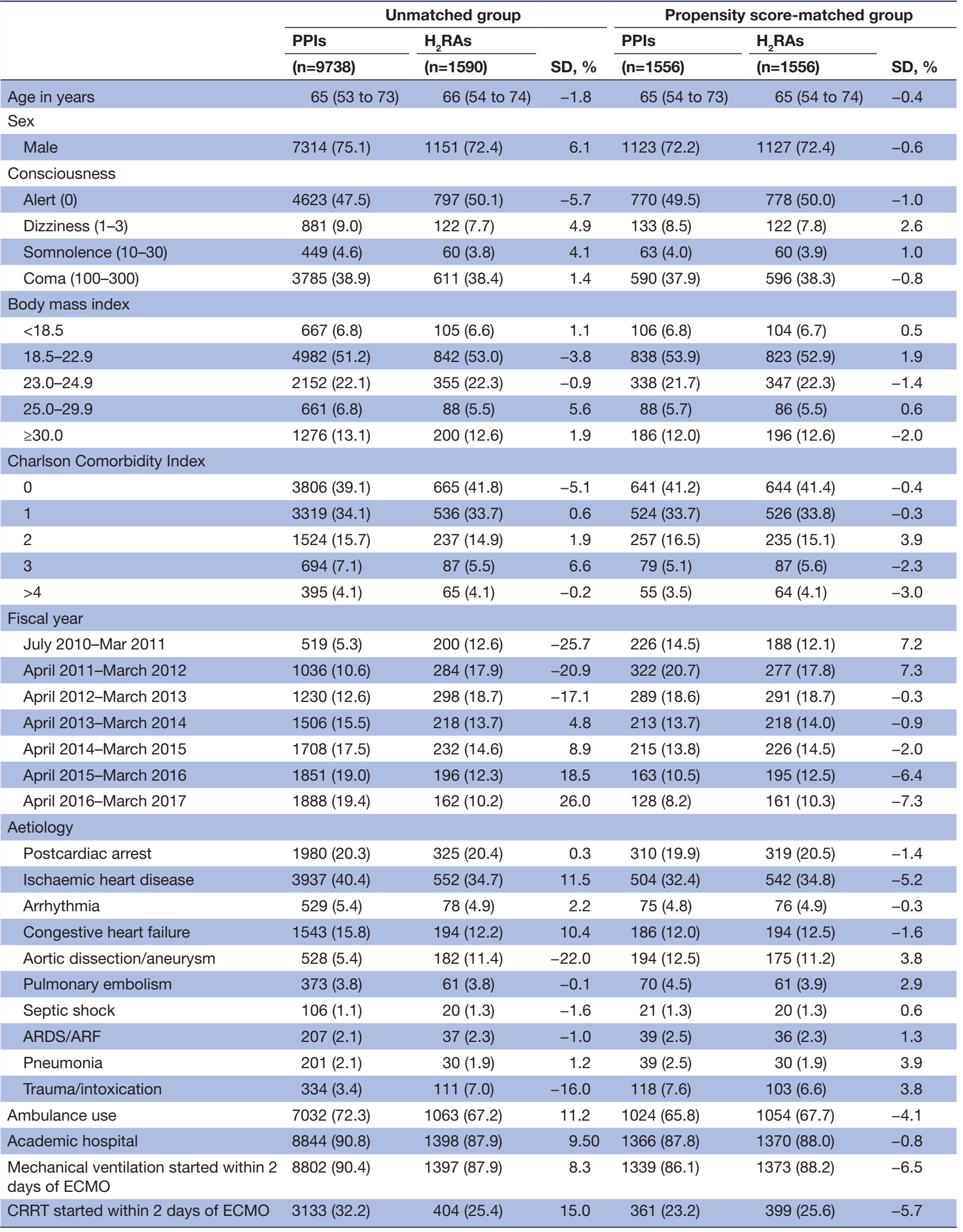




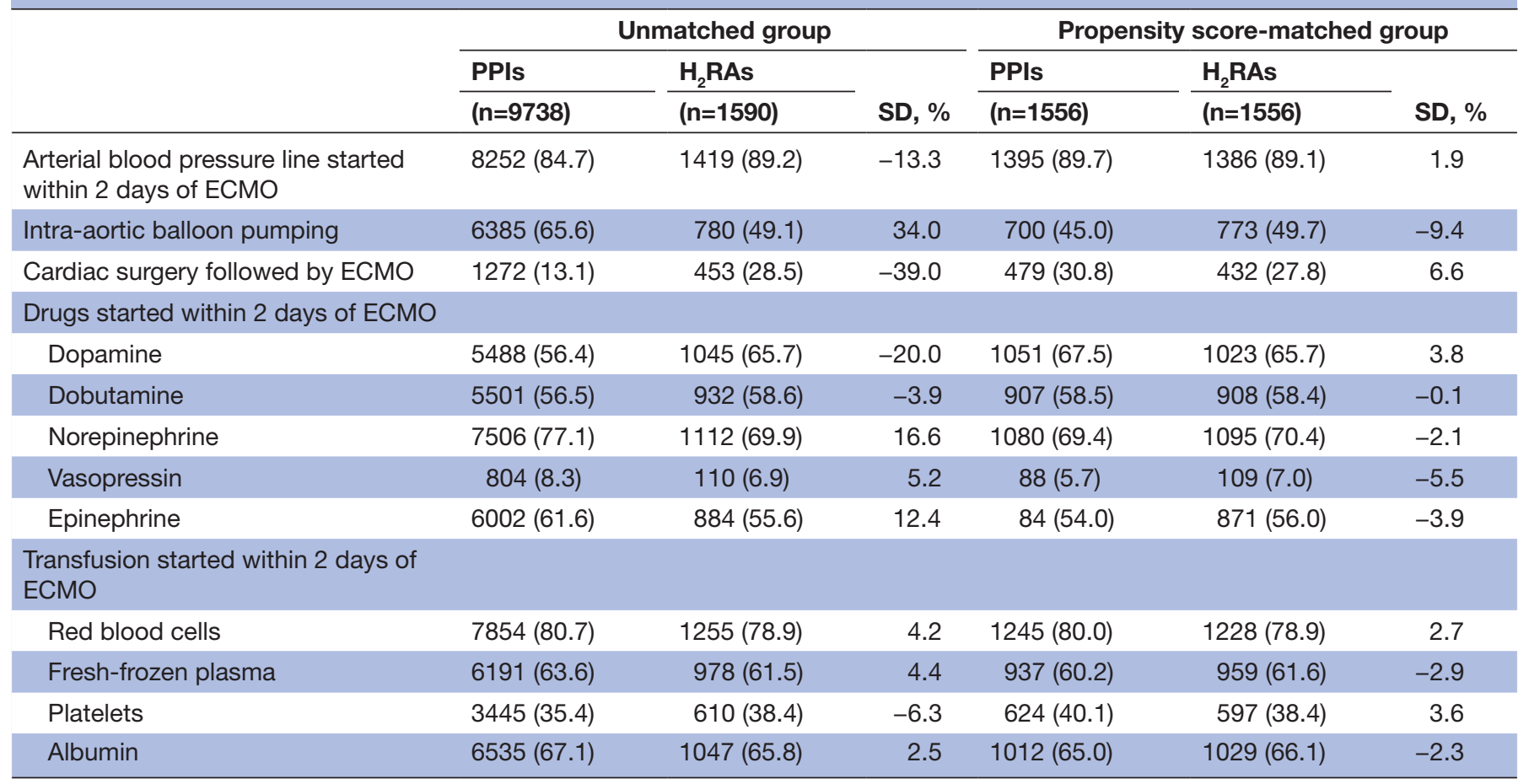

Data are presented as number (\%) except for median (IQR) for age.

ARDS, acute respiratory distress syndrome; ARF, acute respiratory failure; CRRT, continuous renal replacement therapy; ECMO, extracorporeal membrane oxygenation; $\mathrm{H}_{2} \mathrm{RAs}$, histamine-2 receptor antagonists; PPIs, proton pump inhibitors.

difficile infection between the groups. The stabilised IPTW analysis also showed no differences between the groups; therefore, our results are robust.

To the best of our knowledge, ours is the first report comparing PPIs and $\mathrm{H}_{2} \mathrm{RAs}$ for stress ulcer prophylaxis during ECMO. Most previous studies comparing PPIs and $\mathrm{H}_{2} \mathrm{RAs}$ focused on critically ill patients with heterogeneous backgrounds. ${ }^{3}$ CIGIB is pronounced in ECMO patients because of the required high doses of heparin and the mechanically high blood flow rates. Thus, complications related to haemorrhage in ECMO are frequent and have a significant negative impact on outcomes. ${ }^{23}$

Our results showed no significant differences for in-hospital mortality or the proportions of patients requiring endoscopic haemostasis, similar to results in previous randomised controlled trials. ${ }^{24-26}$ Some previous studies have shown conflicting results regarding the efficacy of PPIs and $\mathrm{H}_{2} \mathrm{RAs}$ for stress ulcer prophylaxis. ${ }^{72}$ In the present study, we found no significant difference in $C$. difficile infection rates between patients receiving PPIs versus $\mathrm{H}_{2} \mathrm{RAs}$ for stress ulcer prophylaxis. Previous studies showed that stress ulcer medical prophylaxis increased the risk of $C$. difficile infection, but it remains unclear whether the risk of $C$. difficile infection differs between patients receiving PPIs versus $\mathrm{H}_{2} \mathrm{RAs} .{ }^{28}{ }^{29}$ C. difficile infection and community-acquired pneumonia may occur because of gastric acid suppression. Our results indicate that either PPIs or $\mathrm{H}_{2} \mathrm{RAs}$ can be used.

In a previous study, endoscopic therapy was feasible and helped to achieve complete bleeding control,

Table 2 Outcomes in the unmatched and propensity score-matched groups

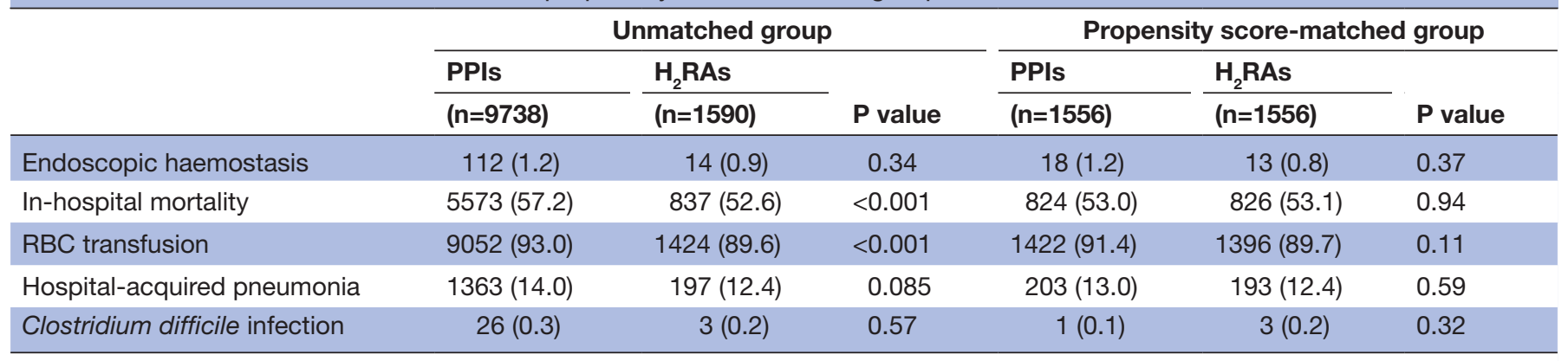

Data are presented as number (\%).

$\mathrm{H}_{2} \mathrm{RAs}$, histamine-2 receptor antagonists; PPIs, proton pump inhibitors; RBC, red blood cells. 
Table 3 Logistic regression analyses of the outcomes fitted using with a generalised estimation equations for the outcomes in the propensity-score-matched population

\begin{tabular}{|c|c|c|c|}
\hline & & ORs & P value \\
\hline \multirow{2}{*}{$\begin{array}{l}\text { Endoscopic } \\
\text { haemostasis }\end{array}$} & $\mathrm{H}_{2} \mathrm{RAs}$ & Reference & \\
\hline & PPIs & 1.39 (0.65 to 2.99$)$ & 0.40 \\
\hline \multirow[t]{2}{*}{ In-hospital mortality } & $\mathrm{H}_{2} \mathrm{RAs}$ & Reference & \\
\hline & PPIs & 0.99 (0.79 to 1.25$)$ & 0.96 \\
\hline \multirow{2}{*}{$\begin{array}{l}\mathrm{RBC} \text { transfusion } \\
\text { rate }\end{array}$} & $\mathrm{H}_{2} \mathrm{RAs}$ & Reference & \\
\hline & PPIs & 1.22 (0.89 to 1.66$)$ & 0.22 \\
\hline \multirow{2}{*}{$\begin{array}{l}\text { Hospital-acquired } \\
\text { pneumonia }\end{array}$} & $\mathrm{H}_{2} \mathrm{RAs}$ & Reference & \\
\hline & PPIs & 1.06 (0.84 to 1.34$)$ & 0.63 \\
\hline \multirow{2}{*}{$\begin{array}{l}\text { Clostridium difficile } \\
\text { infection }\end{array}$} & $\mathrm{H}_{2} \mathrm{RAs}$ & Reference & \\
\hline & PPIs & 0.38 (0.03 to 3.19$)$ & 0.34 \\
\hline
\end{tabular}

Data are presented as ORs $(95 \% \mathrm{Cl})$.

$\mathrm{H}_{2}$ RAs, histamine-2 receptor antagonists; PPIs, proton pump inhibitors; RBC, red blood cells.

and the data showed that it may contribute to reduced mortality. ${ }^{30}$ Our study showed no differences in mortality between the groups, which may have occurred because of the similar proportions of patients achieving endoscopic haemostasis.

This study has several limitations. First, information on the type of gastric ulcer and laboratory data such as serum haemoglobin levels were not available in the Diagnosis Procedure Combination Database. Second, the proportion of patients with gastrointestinal bleeding may have been underestimated because we included only patients with severe bleeding requiring endoscopic haemostasis. Third, we could not exclude all patients with previously diagnosed gastric ulcers or gastritis. Finally, this was a retrospective study, and recorded diagnoses were less well validated than those in prospective registries.

Table 4 Logistic regression analyses of fitted with generalised linear model for the outcomes in stabilised inverse probability of treatment weighted population

\begin{tabular}{|c|c|c|c|}
\hline & & ORs & $P$ value \\
\hline $\begin{array}{l}\text { Endoscopic } \\
\text { haemostasis }\end{array}$ & $\begin{array}{l}\mathrm{H}_{2} \mathrm{RAs} \\
\text { PPIs }\end{array}$ & $\begin{array}{l}\text { Reference } \\
1.48(0.74 \text { to } 2.99)\end{array}$ & 0.27 \\
\hline In-hospital mortality & $\begin{array}{l}\mathrm{H}_{2} \mathrm{RAs} \\
\text { PPIs }\end{array}$ & $\begin{array}{l}\text { Reference } \\
1.00(0.85 \text { to } 1.17)\end{array}$ & 0.98 \\
\hline RBC transfusion & $\begin{array}{l}\mathrm{H}_{2} \mathrm{RAs} \\
\text { PPIs }\end{array}$ & $\begin{array}{l}\text { Reference } \\
1.04(0.81 \text { to } 1.33)\end{array}$ & 0.77 \\
\hline $\begin{array}{l}\text { Hospital-acquired } \\
\text { pneumonia }\end{array}$ & $\begin{array}{l}\mathrm{H}_{2} \mathrm{RAs} \\
\text { PPls }\end{array}$ & $\begin{array}{l}\text { Reference } \\
1.01(0.82 \text { to } 1.25)\end{array}$ & 0.92 \\
\hline $\begin{array}{l}\text { Clostridium difficile } \\
\text { infection }\end{array}$ & $\begin{array}{l}\mathrm{H}_{2} \mathrm{RAs} \\
\text { PPls }\end{array}$ & $\begin{array}{l}\text { Reference } \\
1.63(0.47 \text { to } 5.67)\end{array}$ & 0.44 \\
\hline
\end{tabular}

Data are presented as ORs $(95 \% \mathrm{Cl})$.

$\mathrm{H}_{2} \mathrm{RAs}$, histamine-2 receptor antagonists; PPIs, proton pump inhibitors; RBC, red blood cells.

\section{CONCLUSIONS}

No significant differences in endoscopic haemostasis or in-hospital mortality were shown between the PPIs and $\mathrm{H}_{2} \mathrm{RAs}$ groups in this study. Both PPIs and $\mathrm{H}_{2} \mathrm{RAs}$ are treatment options for stress ulcer prophylaxis in patients receiving ECMO.

Contributors YK conceived this study, analysed the data and drafted the manuscript. HO, HM and KF collected and analysed the data. HY and HT revised the design and manuscript. All authors checked and agreed on the final manuscript.

Funding This work was supported by grants from the Ministry of Health, Labour and Welfare, Japan (19AA2007 and H30-Policy-Designated-004) and the Ministry of Education, Culture, Sports, Science and Technology, Japan (17H04141).

Competing interests None declared.

Patient consent for publication Not required.

Ethics approval This study was approved by the Institutional Review Board of The University of Tokyo Hospital.

Provenance and peer review Not commissioned; externally peer reviewed.

Data availability statement Data may be obtained from a third party and are not publicly available.

Open access This is an open access article distributed in accordance with the Creative Commons Attribution Non Commercial (CC BY-NC 4.0) license, which permits others to distribute, remix, adapt, build upon this work non-commercially, and license their derivative works on different terms, provided the original work is properly cited, appropriate credit is given, any changes made indicated, and the use is non-commercial. See: http://creativecommons.org/licenses/by-nc/4.0/.

ORCID iD

Yutaka Kondo http://orcid.org/0000-0003-1072-7089

\section{REFERENCES}

1 Fernando SM, Qureshi D, Tanuseputro P, et al. Mortality and costs following extracorporeal membrane oxygenation in critically ill adults: a population-based cohort study. Intensive Care Med 2019;45:1580-9.

2 Thomas J, Kostousov V, Teruya J. Bleeding and thrombotic complications in the use of extracorporeal membrane oxygenation. Semin Thromb Hemost 2018;44:020-9.

3 Barkun AN, Bardou M, Pham CQD, et al. Proton pump inhibitors vs. histamine 2 receptor antagonists for stress-related mucosal bleeding prophylaxis in critically ill patients: a meta-analysis. $\mathrm{Am} \mathrm{J}$ Gastroenterol 2012;107:507-20.

4 Alhazzani W, Alenezi F, Jaeschke RZ, et al. Proton pump inhibitors versus histamine 2 receptor antagonists for stress ulcer prophylaxis in critically ill patients: a systematic review and meta-analysis. Crit Care Med 2013;41:693-705

5 Alshamsi F, Belley-Cote E, Cook D, et al. Efficacy and safety of proton pump inhibitors for stress ulcer prophylaxis in critically ill patients: a systematic review and meta-analysis of randomized trials. Crit Care 2016;20:120.

6 MacLaren R, Reynolds PM, Allen RR. Histamine-2 receptor antagonists vs proton pump inhibitors on gastrointestinal tract hemorrhage and infectious complications in the intensive care unit. JAMA Intern Med 2014;174:564-74.

7 Lilly CM, Aljawadi M, Badawi O, et al. Comparative effectiveness of proton pump inhibitors vs histamine type 2 receptor blockers for preventing clinically important gastrointestinal bleeding during intensive care: a population-based study. Chest 2018;154:557-66.

$8 \mathrm{Krag} \mathrm{M}$, Marker S, Perner A, et al. Pantoprazole in patients at risk for gastrointestinal bleeding in the ICU. N Engl J Med 2018;379:2199-208.

9 Yasunaga $\mathrm{H}$, Matsui $\mathrm{H}$, Horiguchi $\mathrm{H}$, et al. Clinical epidemiology and health services research using the diagnosis procedure combination database in Japan. Asian Pac J Dis Manage 2013;7:1-2.

10 Yamana $\mathrm{H}$, Moriwaki M, Horiguchi $\mathrm{H}$, et al. Validity of diagnoses, procedures, and laboratory data in Japanese administrative data. $J$ Epidemiol 2017;27:476-82.

11 Shigematsu K, Nakano H, Watanabe Y. The eye response test alone is sufficient to predict stroke outcome--reintroduction of Japan Coma Scale: a cohort study. BMJ Open 2013;3:e002736. 
12 Quan H, Li B, Couris CM, et al. Updating and validating the Charlson comorbidity index and score for risk adjustment in hospital discharge Abstracts using data from 6 countries. Am J Epidemiol 2011;173:676-82.

13 Yamana $\mathrm{H}$, Matsui $\mathrm{H}$, Fushimi K, et al. Procedure-based severity index for inpatients: development and validation using administrative database. BMC Health Serv Res 2015;15:261.

14 Yamana $\mathrm{H}$, Matsui $\mathrm{H}$, Sasabuchi $\mathrm{Y}$, et al. Categorized diagnoses and procedure records in an administrative database improved mortality prediction. J Clin Epidemiol 2015;68:1028-35.

15 Griswold ME, Localio AR, Mulrow C. Propensity score adjustment with multilevel data: setting your sites on decreasing selection bias. Ann Intern Med 2010;152:393-5.

16 Rosenbaum PR, Rubin DB. Constructing a control group using multivariate matched sampling methods that incorporate the propensity score. Am Stat 1985;39:33-8.

17 Austin PC. Balance diagnostics for comparing the distribution of baseline covariates between treatment groups in propensity-score matched samples. Stat Med 2009;28:3083-107.

18 Leuven E, Sianesi B. PSMATCH2: Stata module to perform full Mahalanobis and propensity score matching, common support graphing, and covariate imbalance testing, statistical software components S432001. Boston College Department of Economics, 2003.

19 Miglioretti DL, Heagerty PJ. Marginal modeling of nonnested multilevel data using standard software. Am J Epidemiol 2007;165:453-63.

20 Liang K-YEE, Zeger SL. Longitudinal data analysis using generalized linear models. Biometrika 1986;73:13-22.

21 Xu S, Ross C, Raebel MA, et al. Use of stabilized inverse propensity scores as weights to directly estimate relative risk and its confidence intervals. Value Health 2010;13:273-7.

22 Austin PC. An introduction to propensity score methods for reducing the effects of confounding in observational studies. Multivariate Behav Res 2011;46:399-424.
23 Oude Lansink-Hartgring A, de Vries AJ, Droogh JM, et al. Hemorrhagic complications during extracorporeal membrane oxygenation - The role of anticoagulation and platelets. J Crit Care 2019;54:239-43.

24 Kantorova I, Svoboda P, Scheer P, et al. Stress ulcer prophylaxis in critically ill patients: a randomized controlled trial. Hepatogastroenterology 2004;51:757-61.

25 Conrad SA, Gabrielli A, Margolis B, et al. Randomized, double-blind comparison of immediate-release omeprazole oral suspension versus intravenous cimetidine for the prevention of upper gastrointestinal bleeding in critically ill patients. Crit Care Med 2005;33:760-5.

26 PEPTIC Investigators for the Australian and New Zealand Intensive Care Society Clinical Trials Group, Alberta Health Services Critical Care Strategic Clinical Network, and the Irish Critical Care Trials Group, Young PJ, Bagshaw SM, et al. Effect of stress ulcer prophylaxis with proton pump inhibitors vs histamine-2 receptor blockers on in-hospital mortality among ICU patients receiving invasive mechanical ventilation: the peptic randomized clinical trial. JAMA 2020;323:616-26.

27 Levy MJ, Seelig CB, Robinson NJ, et al. Comparison of omeprazole and ranitidine for stress ulcer prophylaxis. Dig Dis Sci 1997;42:1255-9.

28 Dial S, Delaney JAC, Barkun AN, et al. Use of gastric acidsuppressive agents and the risk of community-acquired Clostridium difficile-associated disease. JAMA 2005;294:2989-95.

29 Barbateskovic M, Marker S, Granholm A, et al. Stress ulcer prophylaxis with proton pump inhibitors or histamin-2 receptor antagonists in adult intensive care patients: a systematic review with meta-analysis and trial sequential analysis. Intensive Care Med 2019;45:143-58.

30 Amata M, Martucci G, Granata A, et al. The role of endoscopy as non-invasive procedure to manage gastrointestinal complications during extracorporeal membrane oxygenation. Perfusion 2020;10:267659120909669. 